\title{
Improvisos fragmentados \\ entalhos de dissertação \\ fisiolosofia \\ em \\ construção
}

\section{Carol Barreiro}

1.1 Que toda pesquisa tem início em um determinado momento da sua vida é fato. É o feito. Mas nunca saberemos se o que descobrimos é o inicio de uma pesquisa, ou apenas um olhar de pesquisador para o que a própria vida já faz. Pois então haveria de fato fórmula precisa para falar sobre o que ela já é, traçando uma impessoalidade distanciada que obtém como objeto de pesquisa a própria vida? Sujeito e objeto, para o artista, no caso a bailarina, já sabemos, não partem de locais separados, e sim compactuam-se nesse novo desejo de se fazer escrito, reformulado, arquitetado na criação do encontro entre fala, pensamento e arte. O que começamos de fato talvez seja o simples exercício de usar o conceito na dança do pensamento, pois nos debruçamos diariamente sobre os gestos, nos movimentos, na ação silenciosa em improvisação constante, abertamente dirigidos ao fora na expressão que adentra a sensação, na sociabilização de uma comunicação dançante. Vislumbramos o conceito muitas vezes como um horizonte distante a ser conquistado, mas nunca experimentado. E quantas foram as paralisias em que um imperativo do pensamento parecia se contorcer nos abismos da teoria, supostamente nos distanciando da prática que a vida é, fazendo o corpo parar frente ao livro e deixar a dança de lado, nos exigindo a abordagem histórica e o repertório monumental daqueles tantos escritos que não conhecíamos. Quantas foram as paragens que quase nos confundiram nas múltiplas direções que o pensamento poderia oferecer. Mas eis que nos voltamos acesos à palavra, sabendo que ela é, também, gesto, inquietos em reverberar as questões colocadas, as teorias envolvidas, nos dissolvendo entre os léxicos verbais e as situações conceituais. Aprendemos também a dançar mesmo na paragem que supõe a postura e a leitura de um livro, exigindo da palavra também seu movimento, sua ação. E desses muitos e inusitados encontros entre a dança e filosofia, surgiram pensadores que carregam na sua escrita uma abertura

${ }^{1}$ Carol Barreiro dança, improvisa e faz contato com pesquisa acadêmica. 
mesma a experiência de si e da própria vida. Um lugar onde teoria e prática possam se encontrar com a exigência maior do pensamento enquanto criação, nos sussurrando com o corpo essa interação real da aliança extrema entre pensamento e ação. Então já não nos é estranha a tarefa de pensar com as ditas palavras e nem de dançar com os conceitos, é pois a exigência de nos fazer também improvisar no silêncio que permite o jogo da linguagem.

6.4 Começo da queda. Talvez aqui seja o momento da queda, ou o começo de um fim. Escrever sobre o silêncio, através dele: é a tarefa do bailarino quando fala sobre o que move. Nada escapa ao fato de que ele pensa mudando de natureza, arremesso da investigação do próprio tempo, mas extemporâneo também, pois é sobre os gestos que se apresentam no imediato a sua matéria de investigação. Que lida com a gravidade, joga, cai, contrai, expande, pesa, mas não na condição do sujeito que recebe a intenção da ação, não há sujeito na sintaxe dos afectos, nem o nada sem dança do antes sucede o agora do movimento, o ato não antecipado. É sobre o tempo que cria e a consciência que impõe. A comunicação deste longo arremesso em que, situado no acontecimento do mover, apodera a matéria de sua incapacidade de pausa, articula a mobilidade do pensamento que rasga o hábito da convenção moral enquanto palavra de conhecimento inerte. Nossa consciência, nossos gaps não são feitos de faltas, mas de precisões concedidas no emaranhado da espacialidade das forças que atuam no corpo e da incorporação mesma desses movimentos que agem. A matéria de nossa ação refere-se a força afectiva de nossa criação. Ao engravidar a gravidade agimos instantaneamente frente ao improviso que nos concede o agora. O bailarino pensa porque age, e dança porque cria. Sua consciência dança através de um corpo que pensa, e nesse momento em que falamos na língua dos conceitos, apenas sugerimos uma estratégia de conhecer-nos também no entrelaçar com outros movimentos, com outras formas de forças, "pois é preciso saber ocasionalmente perder-se, quando queremos aprender algo das coisas que nós próprios não somos" (NIETZSCHE,2007, p.207). Com essa breve avaliação conceitual, experimentamos também a possibilidade de conscientizarmos da nossa prática através da linguagem verbal, procurando interligá-la com pensadores que voltaram seus experimentos em direção ao corpo e que, dançando em atos linguísticos, articularam-se para além de uma certa moral, pois há também "livros que ensinam a dançar."2

\footnotetext{
2 Título do aforismo 206 do livro Humano Demasiado Humano de Friedrich Nietzsche no qual discorre: “ Há escritores que, por apresentarem o impossível como possível e falarem da moral e do genial como se ambos fossem um mero capricho, um gosto,
} 
3.9 Pensar no susto. Um copo cai e quebra na cozinha do restaurante, todos olham abismados, um certo pânico, silêncio suspenso, três segundos são necessários para a compreensão de "apenas um copo caiu”. Caminhada no parque domingo de manhã, um grito constrangedor dissemina-se no espaço sonoro, pescoços contorcidos, paralisia do cooper, freio da bicicleta, um mendigo rola no chão abraçado em uma garrafa de cachaça, em um momento desdobra-se o fato: "apenas um marginal bêbado a gritar”. Essa suspensão do instante em que há um hiato, uma paralisia, um grau de observação em que ainda reverbera o suspense, uma contração social, uma dúvida entre o pleno terror ou o confortante apaziguamento, um espasmo entre a compreensão narrativa do que representamos para nós mesmos e a repreensão do diafragma que vira foto respiratória. Esse lugar, esse segundo de milésimo, se torna o exato instante em que o bailarino comete uma silenciosa atitude: não esperar pela resolução cognitiva da consciência, mas acioná-la a de fato percebê-la inteira no seu puro acontecimento que surge. Urge. O tempo de significar um fato é lento demais para o reflexo dançado. O susto envolve uma certa concepção de erro, todo acometido que imprevisível chega causando, sem causa certa nem efeito preciso, chega mesmo é causando (no gerúndio). E o que te assusta? Atualmente, nesses experimentos que ando averiguando, ou apenas sugerindo, cada vez mais esse suspense tem levantado os ombros e tensionado os músculos, cada vez mais o susto anuncia um ar denso de terror. Medo. Medo. Medo. Repete a cara do susto levado a sério, aquela ameaça que tem uma resposta eufórica mas ao mesmo tempo paralisada, hesitante e comprometida. Quando se trata de medo o susto não é engraçado, pode causar até infarto, e o tanto de gente que já deve ter morrido de medo de morrer..... Buscamos talvez uma segurança para escapar do susto, pois é nele que vemos surgir uma realidade irrevogável de que há um fora, um outro, um espaço, em que a invasão existe de fato, e de que estar seguro é apenas uma ideia que fazemos para nos sentir menos assustados, menos amedrontados?

4.2 Afectibilidades. Definimos aqui algumas qualidades afectivas de certas emoções como o meio e o modo de evidenciar certos aspectos dos corpos biopolíticos, que culminam no colapso corporal no qual se torna prerrogativa da dança o "entrar no corpo". Encarando o corpo como um campo de 
forças a ser atravessado constantemente pelos acontecimentos ${ }^{3}$, as configurações que o toma como, por exemplo, o medo inserido no susto, sabemos bem, não pode ser generalizada, sendo que cada corpo obedece a um sistema de forças próprio na sua simbiose afectiva. Mas ao problematizá-las segundo uma perspectiva singular de quem aqui escreve, apenas evidenciamos, sem a ideia de uma projeção generalizadora, certos tipos de forças afectivas que perpassam diferentes corpos, mas que receberão e operarão de variadas formas quando submetidos a um determinado impulso. Nesse sentido, talvez seja necessário, como a própria prática do Contato Improvisação nos sugere, evidenciar uma situação perceptiva no qual engendra-se confusamente a relação entre sensação e emoção. Segundo Susana Kelsseman, há uma grande diferença entre essas duas orientações perceptivas:

Hablo de sensación porque considero que las sensaciones son aguijones, pulsos, vibraciones, unidades más pequeñas que las emociones. Las emociones podrían ser pensadas como un conjunto de sensaciones que se articulan y toman diferentes configuraciones a las que llamamos emoción. Doy un ejemplo: frío, oscuridad, humedad, pueden articularse en la emoción de miedo según algunas sensibilidades. Cada persona podrá hacer su propio registro, porque la emoción, desde este tipo de pensamiento corporal que bosquejo, es singular y no valdrían las generalizaciones, aunque exista esa tentación.( KELSSEMAN, 2007, p.24)

O exercício de contrair certas afecções através de um conhecimento emocional pode, tanto conferir graus de generalizações, quanto traçar um dissecamento através de compreensões a cerca da realidade afectiva que carregamos enquanto emoção. No que tange o aspecto perpceptivo do Contato Improvisação, não estamos nos relacionando com a sensação através do discernimento de nossas emoções enquanto estados, mas da mutabilidade afectiva que esse corpo carrega, pretendendo ampliar esse sistema sensorial através de uma velocidade atenta as movimentações ali

\footnotetext{
3 “O corpo não pode, pois, ser pensado no mero registro do somático,, do biológico, daquilo que stricto sensu se denomina fisiologia. O corpo tem a impalpável concretude de um campo de forças, ou de uma superfície de cruzamento de infinitas perspecticas. No corpo fala linguagem dos sinais, a natureza do corpo é de uma semiose infinita.”( GIACOIA, 2002, p.212)
} 
existentes. Isto é, não representamos a dor, o medo, a euforia, a alegria na procura de sua capacidade expressiva, mas procura-se os mínimos afectos que atravessam o corpo e que, querendo ou não, podem se sedimentar enquanto uma emoção. Mas primeiramente proponho uma tentativa de dissecação das emoções que representamos para nós mesmos e que se constituem enquanto paralisias para um corpo que dança. Ao discorrer sobre o medo, o susto, a segurança, evidenciamos um sistema emocional que parece pairar enquanto pensamento e pulsação do corpo coletivo, relacionando com a barreira que certas emoções criam a uma dança e que exige um posicionamento perceptivo aguçado de suas relações afectivas. Corpo colapsado na sala de dissecação.

4.3 Medo. O medo parece articular-se em três movimentos: equilíbrio paralisado pela dúvida, tentativa de afirmação da segurança através da expectativa e remoção da presença pela ânsia. Não seria o medo a indicação crucial de que algo está a sua frente, um impedimento, uma aparição? Tem sempre algo a sua frente: o medo de você não conseguir alcançá-lo, faz com que a ação titubei gerando a dúvida; o medo de permanecer no mesmo lugar reverbera na busca por um outro, por um além, gerando a expectativa; e aquele medo que reverbera no desejo intenso e imenso de que algo deve acontecer, não sabendo muito bem o quê, constitui a ânsia.

4.4 Duvidoso. Equilíbrio: a dúvida no corpo de baile do comum. O equilíbrio no singular sugere que há uma possibilidade de pausa, um lugar vistoso feito de relações estáveis e duráveis em condição de constância, o balanço dos seus pesos em proporção de igualdade. Há desequilíbrios, o caminhar é já uma relação entre a construção e desconstrução de equilíbrios, o cair e o levantar são modos dos equilíbrios ocorrerem. Quanto mais desequilíbrios ocorrem, mais possibilidades tenho de criar equilíbrios. Minha dúvida se encontra na antecipação de todas essas realidades em que o equilíbrio se mostra, deslumbro todas as possibilidades de supor e propor equilíbrios, mas receio quanto penso em testá-los, em acioná-los. Me engole a dúvida da suposição, a realização que possa talvez ser melhor no outro lugar que não é o agora, mas que propõe-se tão maravilhoso quanto esse outro aqui ó, mas que tá do lado do outro que sugere um novo .....etc, etc, etc. Nesse alto vislumbre mental do possível, o equilíbrio é fincado, procurando pela perfeição da proporcionalidade, a paralisia tende a essa tentativa milimétrica de compor todas as igualdade na escolha de uma parte. Esse passeio de suposições não pretende desequilibrar-se, quer mesmo é estar no equilíbrio, pois busca a forma exata de seu comportamental instinto de procura idealizada, sabendo-se atrelado a uma realidade de previsões comparativas de posições estáticas. Nessa busca por um equilíbrio 
perfeito nunca se sai de uma ideia de equilíbrio que é a própria paralisia. Se o movimento necessita de desequilíbrios e descompensações inesperadas, a paralisia da dúvida é esse terreno imóvel da precaução enquanto escolha a ser deslocada apenas na suposição, não na aparição em realidade de mudança. Permaneço no meu ideal de equilíbrio, procurando-o na infinita indecisão. Perceba que para sair do meu lugar busco sempre o melhor lugar, para dar um passo suponho todas as considerações que minha atividade cognitiva possa oferecer enquanto antecipação e previsão do movimento, a escolha enquanto produto de uma subjetividade que pressupõe uma liberdade de ação, atrapalha-se na multiplicidade das sugestões que lhe chegam, das promessas que sua cognição consegue produzir. Titubeio em um passo que for, em uma queda, em um deslize, e nesse momento em que pairo na dúvida supõe uma escolha consciente, que é demasiadamente idealizada para a tarefa da dança, apenas um floreamento sináptico que não compactua com as necessidades da prontidão a que estamos exercitando. Modo de operação do medo: meu equilíbrio é sempre o mesmo, para sair dele devo escolher minuciosamente que movimento fazer. O CI opera por desequilíbrios, não por conjunturas pré-estabelecidas, tentativas de perfeição, conexões diretas com as previsões estáticas que quero dar ao meu território sacralizado por um escolha bem feita- sim, fiz uma escolha bem feita, porque o duvidoso mesmo depois de já ter decidido ainda titubeia na sua indecisão, e por isso deve continuar a afirmar a si mesmo que era o melhor a se ter feito. A dúvida são todas as expectativas incorporadas em uma inação, em um equilíbrio estático.

4.5 Espero. Espero a expectativa da minha segurança. Não pressuponho, espero, há algo firmado em uma segurança inalcançável que concebo rascunhada nesse universo a que pretendo lançar-me, algum dia, não se sabe muito bem quando, nem porquê, espero. Esse horizonte que espreita meus atos, colaborando com uma ideia de que algo melhor há de surgir no conforto que me propõe a segurança, permanece e se comporta como a vantagem de minha inação, no fundo um terreno propício avançará. Expectador dos acontecimentos, de mim mesmo e dos outros, avanço sem avançar, imobilidade convergida na captura de minha busca incessante de aparelhar-me sempre com a possibilidade de um futuro realizável, mas nunca de fato vivido enquanto acontecimento. Sugiro que meu conforto e minha segurança ocorrem não porque no agora tenho um limite bem estipulado de minhas ações, mas que o futuro em mim avança para um fim, sou a sua causa e dele admiro seu possível efeito. Relevo de mim o que não posso fazer no agora enquanto efeito sem causa, mas procuro a realização que converge para uma relação de continuidade característica de minha incessante expectativa de seguridade, de realização, de melhora. Meu otimismo esperançoso 
não só me retira da presença que devo dar atenção, mas da potência de subversão em que não precisaria exigir um final feliz. Minha expectativa elabora as circunstâncias de valores associados a eterna pretensão do que me sugere sucessão, não necessariamente conheço o caminho a traçar, mas dele espero a fantasia da emoção e a alegria da compensação. Nada que em mim pulse extemporâneo, necessário e insurgente conflui para o acontecimento que atenho-me no alcance da expectativa final. $\mathrm{O}$ medo se comporta nessa espera que talvez em nada chegue, que sucessivamente só confirme o inalcançável dessa espera, e que possa se comportar como o inesperado daquilo em que nunca se orientou enquanto expectativa. Meu medo é de que uma ação necessária no presente me faça desviar da minha tão segura expectativa que criei, antes, muitos antes que o agora, mas que avança para esse futuro que esvazia minha presença. Tenho medo de a nada chegar, esse nada fantasiado de coisa alguma reverbera a falta de segurança, e por isso no agora tenho que me presentificar o futuro, com medo de perdê-lo, já que é para ele que corro sem parar. Minha expectativa me faz vencer a morte, pois com ela tenho amanhã, mais do que esse hoje que pode corromper-se sem projeto nenhum nessa influência instantânea do inesperado. Espero, enquanto espero, avanço, para essa minha tão já rascunhada expectativa. Meu medo é a insegurança de não ter amanhã, por isso faço do agora seu futuro.

4.6 Da ânsia. Toda ânsia tem um vômito que não quer sair, mas que apenas reverbera, dilacera internamente seu incômodo, e não se propõe a lidar com o fora. Internaliza seu desconforto corroendo os circuitos nervosos, fala de si sem se mostrar, reverbera um movimento sempre com um peso mal resolvido que insiste em limitar-se. Não respira, soluça. Não expõe, contrai. Condição limitada pelo meu grau de consentimento engessado nas particularidades de minhas formas fixadas, de meus aparelhamentos mal resolvidos, minhas estritas relações petrificadas. Algo que move em medo de ansiedade sem meta, qualquer meta vale o que não se pode mostrar, e não se mostra por incapacidade de perpetuação de algo que dure, sensação de um quase lá que sempre chega exaustivamente sem lugar de realização. Agonia que chega de súbito na condição de uma falta exaustivamente atualizada, medo de que não seja o agora aquele a se demandar, pequena inspiração que nunca se mostra, o que quer o agora, o outro, o novo, esse pulsar do que chega e não se sabe como chega, mas que quer chegar. Torna-se precaução de uma impossibilidade, e por isso mesmo considera-se o terror do agora uma situação de perigo iminente, essa relação com o presente que só se encolhe, estendido em ruminar vagaroso da carência do que não se tem. A tentativa de mostrar-se nunca será completa, não viabiliza singularidades, sempre meio termo, escondida por 
entre alguns dizeres que nunca se expressam mas que consomem o tudo que vem com a afobação de um viciado ou com a rapidez de um esfomeado. Nessa ânsia sem sentido se consome a si mesmo um tempo que não suporta o agora. Medo de permanecer no mesmo lugar nunca nem estando nele.

4.7 Valorar emociona. Que o medo pressupõe espera, dúvida, ânsia, mas o que mesmo adquire uma condição para que estas emoções surjam e se tornem repetidamente uma ação corporal? Nesse lugar em que, condicionada a ação a uma repercussão das qualidades afectivas do corpo, e sujeitada a certas sedimentações emocionais, o que nos revela o susto do imprevisível? Na nossa produtiva subjetividade se encontram impulsos e potências por onde a dança se perpetua, uma atenção perceptiva necessita de uma (des)orientação afectiva para que o movimento se faça. Na imprevisibilidade dos fatos o acometido se torna incerto, uma queda há de reverberar um erro propício, um salto há de lançar-me, talvez, para o outro, mas se o outro mesmo não me segura com sua segurança, sei desviar nessa suposição da falha. Não esperar do outro uma terreno seguro, não esperar. Se medo adquiro em relação ao outro, apenas reajo nesse território, sem uma afirmação dos movimentos que estão em jogo. Nesse intuito, a motricidade não se separa mais da ativa atenção que cartografa os mínimos movimentos e os rápidos acontecimentos com que o corpo lida. $\mathrm{O}$ movimento reflexo é gerado, perante a visão científica, pelo sistema nervoso autônomo, isto é, a informação nervosa não passa necessariamente pelo córtex cerebral, e sim somente pela medula, não obedecendo a uma certa "vontade cortical", a uma consciência cerebral. Mas haveria como chegar nessa velocidade específica de um movimento reflexo sem passar também por uma emoção já impregnada enquanto qualidade afectiva desse mesmo reflexo? O susto, o inesperado, quando sedimentado em uma resposta específica, a do medo, desacelera sua reposta, ou paralisa uma possibilidade de ação. Estipulando realidades que se configuram em relações de repetições nocivas a certas circunstâncias mutáveis, atuando enquanto vícios de ações reativas perto de um possibilidade da afirmação da criação. Nesse sentido trazemos aqui a filosofia de Nietzsche no que se refere aos impulsos ativos e reativos, que tendem a diferenciar-se em ações segundo seu grau qualitativo de afinidade com forças que aumentam ou diminuem a potência do corpo ${ }^{4}$ (NIETZSCHE, 1998). A reatividade se mostra na condição de valores instituídos, sedimentados em emoções como culpa, sofrimento, humildades, etc, que não dão vazão a sua própria potência de afirmação, tornando-se

\footnotetext{
4 Toda a sua obra apresenta os conceitos de ações reativas e ativas que revelam o seu quantum de poder de acordo com a preponderância, ou não, de certos valores instituídos em uma espécie de fisiologia da ação. Onde vemos, dentro das obras publicadas em vida, uma maior dissecação desse conceito é na obra Genealogia da Moral em que se traça um apanhado genealógico de como o homem trouxe o valor de má consciência como fundamentação de suas ações morais.)
} 
reações interiorizadas e justificadas segundo uma consciência moral. A ação ativa busca a expansão e afirmação de si, constituindo-se através da criação de valores, e não da sua mera repetição já estacionada segundo crenças interpretativas que negam os impulsos corporais. Esses dois modos de operação, efetuam-se segundo a capacidade de perpetuar a condição, ou não, de potencialização através da vontade de poder - vontade essa que não se conjectura segundo um fundamento que irá se mostrar na relação com o mundo, mas que se encontra implícita na efetuação mesma dessas relações, nas fricções de forças, é o próprio efetivo na sua efetividade (MÜLLER-LAUTER,1997). As potências do corpo se mostram, muitas vezes, subordinadas a uma má consciência, que se exprime perante ações ressentidas calcadas em valores específicos. Segundo Nietzsche:

A idiossincrasia democrática contra tudo o que domina e quer dominar, o moderno misarquismo (forjando uma palavra feia para uma coisa feia) de tal modo se transformou e se mascarou no que é espiritual, espiritualíssimo, que hoje passo a passo penetra, pode penetrar, nas mais rigorosas e aparentemente mais objetivas ciências; me parece mesmo que já se apossou de toda a fisiologia e teoria da vida, com prejuízo dela, já se estende, ao lhe retirar uma noção fundamental, a de atividade. Sob a influência dessa idiossincrasia, colocou-se me primeiro plano a “adaptação”, ou seja, uma atividade de segunda ordem, uma reatividade; chegou-se mesmo a definir a vida como uma adaptação interna, cada vez mais apropriada, a circunstâncias externas ( Hebert Spencer). Mas com isso se desconhece a essência da vida, a sua vontade de poder, com isto não se percebe a primazia fundamental das forças espontâneas, agressivas, expansivas, criadoras de novas formas, interpretações e direções, forças cuja ação necessariamente precede a "adaptação"; com isto se nega, no próprio organismo, o papel dominante dos mais altos funcionários, aqueles nos quais a vontade de vida parece ativa e conformadora.( NIETZSCHE,1998, p.67).

A concepção de uma ação sempre disposta enquanto resposta a um ataque, uma "subjetividade de defesa", calcada em uma justificativa que recolhe-se ao universo de valores que apenas desagregam cada vez mais as potências no qual o corpo é capaz de ativar, tornando-se 
adaptável perante as variadas situações que o perpassam - não se torna um sedentarismo perceptivo culminando em uma passividade de, apenas, reagir? Não se tornando expansão e sim mera retração, enclausura-se em um consciência estipulada perante o investimento de certos valores calcados em determinadas emoções. Ressentimento, humildade, bondade, medo, emoções que estruturam e orientam o modo de operação da ação corporal e que se tornaram, perante a relação em que se orientaram tanto o pensamento religioso, como científico, filosófico e artístico, uma construção e manutenção subjetiva ligada a concepção de certos valores. Essa construção que, segundo Nietzsche, foi instruída e disseminada segundo uma moral judaico-cristã, culminando no aparecimento de valores que interiorizam os investimentos de uma potência criadora, torna o corpo uma doença, pois utiliza-se sempre uma ação de defesa, um movimento reflexo que supõe uma paralisa, uma adaptação sem dominação. Sabendo que estes lugares, estes momentos em que o corpo passa por construções morais, sedimentações emocionais, valorações reativas, também deve ser vivido e experimentando, pois ultrapassá-los exige conhecê-los, mas esse conhecimento, uma vez estacionado em apenas uma possibilidade unidirecional de resposta, necessita também colapsar. Tensão do reflexo: o saber do colapso é o início do movimento. Mas que tipo de movimento corporal avança além das emoções reativas? Que tipo de consciência atinge o bailarino para que a dança ocorra nesse lugar de atuação ativa de seus reflexos?

6.4 Começo da queda. Talvez aqui seja o momento da queda, ou o começo de um fim. Escrever sobre o silêncio, através dele: é a tarefa do bailarino quando fala sobre o que move. Nada escapa ao fato de que ele pensa mudando de natureza, arremesso da investigação do próprio tempo, mas extemporâneo também, pois é sobre os gestos que se apresentam no imediato a sua matéria de investigação. Que lida com a gravidade, joga, cai, contrai, expande, pesa, mas não na condição do sujeito que recebe a intenção da ação, não há sujeito na sintaxe dos afectos, nem o nada sem dança do antes sucede o agora do movimento, o ato não antecipado. É sobre o tempo que cria e a consciência que impõe. A comunicação deste longo arremesso em que, situado no acontecimento do mover, apodera a matéria de sua incapacidade de pausa, articula a mobilidade do pensamento que rasga o hábito da convenção moral enquanto palavra de conhecimento inerte. Nossa consciência, nossos gaps não são feitos de faltas, mas de precisões concedidas no emaranhado da espacialidade das forças que atuam no corpo e da incorporação mesma desses movimentos que agem. A matéria de nossa ação refere-se a força afectiva de nossa criação. Ao engravidar a gravidade agimos instantaneamente frente ao improviso que nos concede o agora. O bailarino pensa porque age, e 
dança porque cria. Sua consciência dança através de um corpo que pensa, e nesse momento em que falamos na língua dos conceitos, apenas sugerimos uma estratégia de conhecer-nos também no entrelaçar com outros movimentos, com outras formas de forças, "pois é preciso saber ocasionalmente perder-se, quando queremos aprender algo das coisas que nós próprios não somos" (NIETZSCHE,2007, p.207). Com essa breve avaliação conceitual, experimentamos também a possibilidade de conscientizarmos da nossa prática através da linguagem verbal, procurando interligá-la com pensadores que voltaram seus experimentos em direção ao corpo e que, dançando em atos linguísticos, articularam-se para além de uma certa moral, pois há também "livros que ensinam a dançar."5

- KELSSELMAN,Susana. El pensamiento corporal: biopolítica de las sensaciones. Revista TOPIA - psicoanalisis,sociedad,cultura, edição La Sociedad del Asfalto. Buenos Aires: Año XVIII, n.49, abril/julho 2007.

- MÜlleR-LAUTER, Wolfgang. A Doutrina da Vontade de Poder em Nieztsche. São Paulo: Anablume,1997.

- $\quad$ NIETZSCHE, Friedrich. Genealogia da Moral. São Paulo: Cia das Letras, 1998.

- $\quad$ NIETZSCHE,Friedrich. Gaia Ciência. São Paulo: Cia das Letras, 2007.

\footnotetext{
5 Título do aforismo 206 do livro Humano Demasiado Humano de Friedrich Nietzsche no qual discorre: “ Há escritores que, por apresentarem o impossível como possível e falarem da moral e do genial como se ambos fossem um mero capricho, um gosto, provocam um sentimento de liberdade exuberante, como se o homem se colocasse na ponta dos pés e tivesse absolutamente que dançar por prazer interior”. (NIETZSCHE, 2013)
} 